\title{
Economia (e política) do moderno
}

\author{
Ettore Finazzi-Agrò ${ }^{2}$
}

\section{Resumo}

$\mathrm{Na}$ análise do intercâmbio cultural entre o Brasil modernista e a Europa das vanguardas devemos, a meu ver, sempre ter em conta certo unilateralismo do desejo, construindo um fetiche (um totem, na terminologia de Freud utilizada por Oswald de Andrade) do ausente e do barrado (do $t a b u$, sempre no re-uso, feito pelo escritor brasileiro do vocabulário freudiano), que ou pode ser incorporado através do ato canibalesco, ou permanecer no seu estado latência, de objeto inalcançável, produzindo, por isso, aquela dobra melancólica que atravessa os anos 20 do século passado (e se prolonga no começo da década seguinte), se cruzando, aliás, com a euforização da ausência e com a exaltação da mestiçagem. A análise é centrada na análise contrastiva dos manifestos oswaldianos, definindo o espaço "econômico" do Moderno nos seus embates com a construção "política" de uma cultura autenticamente nacional.

\section{Palavras-chave}

Modernismo, vanguardas, Dom, troca.

1 Texto da palestra proferida pela autor no IEB a 7 de outubro de 2009 , por ocasião do lançamento do número 49 desta revista. Numa versão semelhante, apareceu em livro coletivo publicado pela Abralic.

2 Professor da Universidade “La Sapienza” de Roma, Itália. E-mail: finazzi@uniromaı.it 


\title{
Economics (and politics) of the Modern
}

\section{Ettore Finazzi-Agrò}

\begin{abstract}
In the analysis of the cultural exchange between modernist Brazil and avant-garde Europe, one must, in my view, always bear in mind a certain unilateralism of desire, constructing a fetish (a totem, in Freud's terminology used by Oswald de Andrade) of the absent and of the barred (of the taboo, to stay with the re-use of the Freudian vocabulary made by the Brazilian writer). This may either be incorporated through the cannibalistic act or remain in its latent state, that of an unreachable object, thus producing that melancholic fold throughout the 1920s (and stretching into the following decade), which, incidentally, blends with the 'euphorization' of absence and the exaltation of human admixture. The analysis is centered on contrasting the Oswaldian manifestos, defining the "economic" space of the Modern in its battles with the "political" construction of an authentically national culture.
\end{abstract}

Keywords

Modernism, avant-gardes, Gift, exchange. 
devorando-o. Naquela altura, eu já tinha, por um lado, decidido falar aqui da relação entre o Dom e a Troca, a partir do modernismo paulista, e, por outro, eu estava relendo, para a minha aula, o Retrato do Brasil e outros clássicos de interpretação da Nação, publicados pouco depois dele. Nessa conjuntura, a interpretação freudiana da melancolia calhava de modo inesperado, redistribuindo, de forma totalmente nova, os dados da questão colocada pelos modernistas. Que eu saiba, com efeito, muitos apontaram para o papel desempenhado por Paulo Prado não só na organização da Semana, mas, em sentido mais geral, na construção e apoio ao movimento intelectual e artístico paulista. Aquilo que sempre ficou na sombra, aquilo que ficou substancialmente não dito foi o modo como funciona a proposta de uma leitura "melancólica" do Brasil, avançada pelo ilustre cafeicultor dentro do panorama substancialmente eufórico da época.

No mesmo ano-chave de 1928 foram de fato publicados, como se sabe, por um lado, o Manifesto antropófago e Martim Cererê, e, pelo outro, Macunaíma e, justamente, Retrato do Brasil: o problema é saber, de saída, de que modo esses textos germinais funcionam e inter-agem entre si, isto é, se seria enfim legítimo agrupá-los e distanciá-los como fiz, colocando-os em lugares distintos, desenhando, em boa medida, um paradigma textual. Nessa perspectiva, a leitura de Freud consegue embaralhar as cartas do imaginário modernista, apontando para um elemento que junta todos esses textos (e muitos outros) numa outra constelação de sentido, que não tem apenas a ver com a reafirmação polimorfa da identidade nacional (identidade triste e resignada em Paulo Prado, identidade alegre e agressiva em Oswald, identidade mestiça em Cassiano Ricardo, identidade plural e, ao mesmo tempo, ausente em Mário), mas que projeta a questão identitária em sua relação complexa com a alteridade. Com efeito - e não sem algum embaraço - Freud aponta para uma diferença importante entre o luto e a melancolia, visto que a segunda denuncia uma perda "mas sem que se consiga saber claramente aquilo que se perdeu"4. Um conhecido filósofo italiano (Giorgio Agamben), comentando esse aspecto, escreveu:

Poderia se dizer que a retração da libido melancólica não tenha outro fim que o de tornar possível uma apropriação numa situação em que nenhuma posse é, na realidade, possível. Nesta perspectiva, a melancolia não seria tanto a reação regressiva à perda do

4 FREUD, Sigmund. op. cit., p. 104. 
objeto do amor, quanto a capacidade fantasmática de apresentar como perdido um objeto de que não podemos nos apoderar. ${ }^{5}$

O Outro, na impossibilidade de ser alcançado no plano real, torna-se, então, o objeto recalcado do desejo: um fantasma alimentando, por isso, a fantasia de uma apropriação que só pode ser realizada na assimilação - no canibalismo, enfim, destruindo e, ao mesmo tempo, incorporando aquilo que se deseja. Nesse sentido, não por acaso Freud incluía entre os casos de excesso de humor negro de sua época os atos de antropofagia, constelando as crônicas dos jornais europeus e os boletins de psiquiatria legal dos finais do século $\mathrm{XIX}^{6}$.

$\mathrm{Na}$ análise do intercâmbio cultural entre o Brasil modernista e a Europa das vanguardas devemos, a meu ver, sempre ter em conta esse unilateralismo do desejo, construindo um fetiche (um totem, na terminologia de Freud utilizada por Oswald de Andrade) do ausente e do barrado (do tabu, sempre no re-uso, feito pelo escritor paulista, do vocabulário freudiano), que ou pode ser incorporado por meio do ato canibalesco, ou permanecer no seu estado de latência, de objeto inalcançável, produzindo, por isso, aquela dobra melancólica que atravessa os anos 20 do século passado (e se prolonga no começo da década seguinte), se cruzando, aliás, com a euforização da ausência e com a exaltação da mestiçagem. Nessa constelação de sentidos heterogêneos, nada fica, obviamente, estável, mas tudo balança e muda de posição dentro de um paradigma de relações momentâneas e plurais em que o nexo entre identidade e diferença transforma-se em novelo, em trama emaranhada da qual é impossível extrair um significado uno e irreversível, que não seja, justamente, a organização arlequinal do sujeito de que nos fala Mário na sua primeira produção poética.

No âmbito das diferenças e das trocas culturais, a questão fundamental, nessa perspectiva, fica a posse e as relações de poder entre o Eu, que fala e deseja, e o objeto falado/desejado - questão na qual está dobrado também o problema, propriamente histórico, da relação entre passado e presente, entre arcaico e moderno, entre memória e esquecimento, entre tradição e inovação. Ou seja, as relações entre culturas não são apenas ditadas por uma situação de supremacia e/ou de dependência (o que é óbvio), mas nelas se inscreve também um projeto de comunidade,

5 AGAMBEN, Giorgio. Stanze: la parola e il fantasma nella cultura occidentale. Torino: Einaudi, 1977. p. 25-26.

6 Sobre este aspecto e sobre a relação entre melencolia e fetichismo, cf. ainda AGAMBEN, Giorgio. Stanze: la parola e il fantasma nella cultura occidentale. op.cit., p. 27. 
fundado sobre a reivindicação de uma autonomia, pretendendo, por sua vez, uma profundidade temporal e uma autonomia territorial. Poderíamos até afirmar, nesse sentido, que o reconhecimento das diferenças pressupõe a aceitação da "indiferença", isto é, da assimilação dos semelhantes dentro de um contexto comum em que tudo se iguala, ou pelo menos, circunscreve um "lugar comum", no qual uma história, finalmente, se instala ${ }^{7}$.

Para explicar tudo isso, basta talvez citar um trecho, aliás muito conhecido, do Manifesto antropófago:

Já tínhamos o comunismo. Já tínhamos a língua surrealista. A idade de ouro.

Catiti Catiti

Imara Notiá

Notiá Imara

Ipeju.

A tentativa de criar uma tradição, de deitar uma ponte entre o arcaico e o moderno para "construir uma comunidade", é aqui explícita e leva ao reconhecimento de um "nós" anterior a qualquer influência ideológica ou fluxo cultural proveniente de um fora, que é, deste modo, reafirmado e negado na sua diferença. Oswald, então, reconhecendo a importância duma ideologia e duma poética "estrangeiras", que chegam de um espaço e de um tempo diferentes, reinscreve tudo isso na indiferença de um "ter já”, fundando assim uma espécie de koiné cultural que identifica e é identificada por uma lógica, por uma história, por uma linguagem peculiares, recortadas, por sua vez, dentro de uma visão alheia. Ou seja, a identidade postulada pelos modernistas é, ao mesmo tempo, fruto de uma extroversão, acolhendo a alteridade, e de uma introversão que a nega, tornando o Outro uma espécie de fantasma, manifestando-se nas entranhas do corpo próprio - e tudo isso, repare-se, graças a uma inversão temporal que torna atual o arcaico e vice-versa, dentro, enfim, de um improvável futuro do passado.

A identidade nacional, a base sobre a qual assenta o "nós" consistiria, de fato, nesse caráter residual, não apenas enquanto produto de uma devoração e metabolização da diferença, mas também como sobrevivência do antigo no novo e como emergência contínua do novo no antigo,

7 Em geral, sobre a questão da comunidade como aquilo que se define na "indiferença", no "qualquer-que-seja”, cf. AGAMBEN, Giorgio. La comunità che viene. Torino: Einaudi, 200o; FIMIANI, Mariapaola. Paradossi dell'indifferenza. Milano: Angeli, 1994. 
anulando ou reduzindo a puro escombro o hiato temporal entre passado e presente. Não por caso as obras-primas do Modernismo alimentam-se de uma confrontação incessante entre espaços e tempos diferentes ( $M a$ cunaíma deve ser, nesse sentido, considerado exemplar), ficando, todavia, inscritas dentro de uma lógica paradoxal (isto é, fora e longe de qualquer doxa habitual), atualizando a cultura autóctone e empurrando a modernidade para um horizonte mítico que faz dela um tempo que sobra e que resta, uma espécie de avesso da tradição ou de tradição do avesso.

Nessa ótica, ao interrogar sobre a dinâmica dos fluxos culturais dentro de um contexto histórico decisivo como o modernista (tempo de construção de uma dialética intercultural que vai desembocar, com a interferência, claro, de variáveis inesperadas e independentes, na situação atual de globalização e, por outro lado, de sublimação do local), acho que seria bom tentar identificar os modos pelos quais os intelectuais e artistas brasileiros daquela época colocaram-se diante da questão crucial do relacionamento com a cultura europeia e, mais em particular, da apropriação ou distanciamento daquela cultura, no sentido de uma valorização do nacional. Assunto, aliás, muito estudado, mas que eu proporia reler, aqui, na ótica que acabo de esboçar, balançando entre diferença e indiferença, entre exaltação e melancolia, entre desafio e harmonização, entre, enfim, despesa e negociação. Em outras palavras, o ponto de partida poderia ser aquele que indica Renato Cordeiro Gomes - recompondo, por sua vez, outras propostas de "localização" das culturas marginais, apoiando-se em outras hipóteses avançadas, em tempos e lugares distintos, por Silviano Santiago e Homi Bhabha:

Entre assimilação e agressividade, aprendizagem e reação, obediência e rebelião, realiza-se o ritual antropofágico da cultura latino-americana, como sugere Silviano Santiago, aquele que se faz de temporalidades disjuntivas, múltiplas e tensas, temporalidades de entre-lugar, o que desestabiliza o significado da cultura nacional como homogênea, pois é uma cultura dividida no interior dela própria, articulando sua heterogeneidade e seu hibridismo, como sugere Bhabha. ${ }^{8}$

8 GOMES, R. Cordeiro. Deslocamento e distância: viagens e fronteiras na cultura Latino-americana - dramatização de marcas identitárias. In: ABDALA JR, B.; SCARPELLI, M. Fantini (Org.) Portos flutuantes: trânsitos ibero-afro-americanos. São Paulo: Ateliê Editorial/CAPES, 2004. p. 29-30. 
O tema secular das relações entre margem e centro, a questão da dinâmica dos fluxos e refluxos culturais é, como se vê, colocada dentro de um contexto problemático - "flutuante", justamente ${ }^{9}$ - negando a homogeneidade das culturas nacionais e sublinhando, em sentido contrário, o hibridismo na articulação das diferenças, o entre-lugar que se cava no interior de uma situação de acumulação de lugares e tempos heterogêneos e plurais. E, nessa ótica, a proposta modernista de construção de uma atualidade periférica, de uma centralidade deslocada, resulta com certeza decisiva, apontando para a eventualidade de um "sentido comum" e interposto, no qual se reconhece na sua diferença indiferente, na sua exaltação melancólica.

Mas, exatamente porque alimentada pela hibridação de saberes anacrônicos e projetada num horizonte mítico, em que se recupera uma lógica outra e arcaica ("Já tínhamos a língua surrealista. A idade de ouro"...), acho que a relação entre essa cultura marginal e um hipotético centro civilizador possa ser relida também do ponto de vista dos mecanismos de mediação e intercâmbio, tanto econômico-sociais quanto antropológicos e culturais. E, nesse sentido, volta a ser importante e elucidativa a diferença entre a prática do Dom e a sua codificação mercantilista, isto é, entre a dádiva e o hábito jurídico da troca, postulada, primeiro, por Marcel Mauss e estudada, depois, em diversos âmbitos históricos e em diversas perspectivas, por muitos outros estudiosos ${ }^{10}$. Não quero, evidentemente, retomar aqui a noção de largesse, de "dádiva", ao pé da letra, mas apontar apenas para o espaço ambíguo aberto pelo uso (também linguístico, como é mostrado pela antilogia Gift/Gift, i.e., “dom”/“veneno", nas línguas germânicas), pela presença ambivalente, então, desse "Dom envenenado", que encontramos nas culturas arcaicas e em que, talvez, poderia ser resumido também o caráter liminar da cultura brasileira em relação à cultura europeia, a partir da constatação que no ato de doar está presente o duplo movimento de ligação e de antagonismo, de "assimilação e agressividade" - para usar as palavras de Renato Cordeiro Gomes.

9 A referência implícita é, obviamente, ao título do livro citado na nota anterior. No interior dele, gostaria, pelo menos, de ressaltar o belo ensaio (funcional, aliás, à minha análise dos fluxos culturais) de ABDALA JR, Benjamin. Globalização e novas perspectivas comunitárias. In: ABDALA JR, B.; SCARPELLI, M. Fantini (Org.) op. cit., p. 61-72.

10 O famoso Essai sur le don, de Marcel Mauss, publicado pela primeira vez em 1925, abriu, como se sabe, uma ampla discussão, não apenas em âmbito etnológico, continuando até os nossos dias: basta aqui lembrar a existência de La revue du M.A.U.S.S., na qual se continuam debatendo, até hoje, as teorias do famoso antropólogo francês sobre o Dom. 
Poderia ser reinterpretada, nessa perspectiva, a passagem entre a “proposta Pau-Brasil” e a opção pela Antropofagia. De fato, a lógica que superintende o primeiro manifesto oswaldiano é ensopada, como se sabe, por considerações de caráter econômico (“Toda a história bandeirante é a história comercial do Brasil”): baseando-se, enfim, no crescimento impressionante das exportações cafeeiras e na afirmação montante de um ethos capitalista, o autor imposta a relação cultural entre centro e periferia no sentido de uma troca, finalmente perfeita e regulamentada, de bens. A razão econômica aplicada ao universo das relações culturais nos fala, por intermédio de Oswald de Andrade, de um mundo de (id) entidades finalmente (e aparentemente) iguais, subvertendo a lógica da exploração colonialista para implantar, justamente, o domínio da oikonomía, da norma e administração domésticas, pela qual tudo é pactuado a partir do interesse interno, local e nacional que, por sua vez, é fruto duma sobreposição caótica de fenômenos heterogêneos:

O reclame produzindo letras maiores que torres. E as novas formas da indústria, da viação, da aviação. Postes. Gasômetros. Rails. Laboratórios e oficinas técnicas. Vozes e tics de fios e ondas e fulgurações. Estrelas familiares com negativos fotográficos. O correspondente da surpresa física em arte.

A reação contra o assunto invasor, diverso da finalidade.

$[\ldots]$

A Poesia Pau-Brasil é uma sala de jantar domingueira, com passarinhos cantando na mata resumida das gaiolas, um sujeito magro compondo uma valsa para flauta e a Maricota lendo o jornal. No jornal anda todo o presente.

Esse discurso, já em si marcado pelo acúmulo desafinado de elementos diversos, parece ainda atravessado pela mão-dupla de um movimento de dar/receber que não afeta apenas a relação com o Outro externo, com a cultura (até então) hegemônica, mas convoca também restos de uma civilização aparentemente apagada, aquela "originalidade nativa" que se contrapõe à "adesão acadêmica", à arte da "cópia": "Obuses de elevadores, cubos de arranha-céus e a sábia preguiça solar. A reza. O Carnaval. A energia íntima. O sabiá. A hospitalidade um pouco sensual, amorosa. A saudade dos pajés e os campos de aviação militar. Pau-Brasil." 
Oswald, então, parece colocar-se dentro dessa dimensão misturada (ou "sincopada") ${ }^{11}$, em que se amontoam e se combinam lugares e tempos diferentes, para negociar, a partir dela, uma identidade própria e exclusiva, riscada pela alteridade e pelo arcaísmo e todavia não (ou não mais) dependente de outras instâncias culturais ${ }^{12}$.

A nomía do oíkos, a ordem do próprio, embora híbrida, embora fruto de uma negociação, por assim dizer, interna, guarda, todavia, a sua auto-nomia (em sentido pleno, etimológico), em confronto, no plano da troca e do intercâmbio, com uma alteridade que dá e recebe - que dá, sobretudo, a modernidade e recebe, em permuta, o arcaico, ou melhor, o arcaico moderno, o popular enaltecido, retrabalhado artisticamente pela cultura brasileira. Já quatro anos depois, a posição de Oswald parece mudar de modo sensível, visto que no Manifesto antropófago não há mais essa confiança na possibilidade de dialogar, de modo paritário, com a cultura europeia. De fato, aquilo que está em jogo na antropofagia é, justamente, a noção de Dom e, na sua forma extrema, de sacrifício, enquanto entrega, sem contrapartida, de si mesmo. Quase como numa espécie de rito eucarístico, teríamos, nesse sentido, a ver tanto com um sujeito que se sacrifica quanto com um objeto que se compartilha, criando, por isso, uma comunidade, uma oikuméne (termo em que volta, não por acaso, a noção de oíkos, de dimensão doméstica, de "sala de jantar domingueira”) que, no gesto melancólico de comer o corpo do Outro, reafirma, por um lado, a sua identidade, o seu ser como parte integrante de uma "pátria", e marca, pelo outro, a sua dependência, o seu estado de submissão a outras, possíveis "pátrias".

O manifesto de 1928, então, parece abrir aquele espaço, ao mesmo tempo, "generoso" e antagônico, que caracteriza o "código do Dom", em que aquilo que está em jogo é justamente o jogo da luta e do pacto. Se, em outros termos, como apontou Marcel Mauss ${ }^{13}$, a essência do Dom é marcada por uma tríplice obrigação (doar, receber e contracambiar), esse lugar heterogêneo em que ele se coloca é, sim, atravessado pela gratui-

11 Cf. PINCHERLE, M. Caterina. La città sincopata: poesia e identità culturale nella San Paolo degli anni Venti. Roma: Bulzoni, 1999.

12 Como se sabe, Homi Bhabha utiliza o termo negotiation "to convey a temporality that makes it possible to conceive of the articulation of antagonistic or contradictory elements: a dialectic without the emergence of a teleological or transcendent History" (BНABHA, Homi. The location of culture. London; New York: 1994, p. 25). A meu ver, é esta dialética imperfeita aquela na qual parece instalar-se também o discurso oswaldiano, desembocando, quatro anos depois, numa outra forma de "negociação" - desta vez ainda menos ligada a um desenvolvimento dialético como é o "dom".

13 MAUSS, Marcel. Saggio sul dono. Torino: Einaudi, 3. ed., 2002. p. 20-zo. 
dade e pela necessidade, pela cumplicidade e pelo enfrentamento, mas sem que isso consiga apagar "a condição de assimetria e de desequilíbrio entre as diferenças"14, que é constitutivo dessa forma antiga de contrato. Com efeito, considerando que "aquilo que se dá na cessão é apenas o ato de ceder e o desafio a destruir", que "aquilo que se move é apenas a força que prende e confunde coisas e pessoas"15, então, a Antropofagia oswaldiana indicaria uma fase peculiar ("fluida") da dinâmica dos fluxos culturais: uma fase em que ao fechamento na "indiferença", na propriedade e autonomia da Nação, corresponde o gesto gracioso e gratuito da expropriação, da entrega de si mesmo, da "despesa" descontrolada do $\mathrm{Eu}^{16}$. Para explicar melhor, à afirmação inicial "só a Antropofagia nos une. Socialmente. Economicamente. Filosoficamente" e ao desafio consequente "contra todos os importadores de consciência enlatada", parece corresponder uma dispersão dos bens próprios, acumulados por esse "Brasil Caraíba", numa espécie de potlatch que o torna país ou sujeito coletivo de referência para uma nova ordem mundial, do ponto de vista social, econômico e cultural. Não por acaso será justamente esse caráter de Dom, e o regime de dívida por ele instaurado, que Oswald continuará sublinhando e reclamando até o fim de sua vida, mostrando até a exaustão como "o matriarcado de Pindorama" seja o "presente não podendo se tornar presente" ${ }^{\prime 17}$ que a cultura brasileira reclama como Dom sem contrapartida para a cultura europeia.

Na verdade, a situação apresenta-se mais complexa desde o início, visto que, se é verdade que o movimento antropofágico antecede e nega a possibilidade da troca regulamentada do "contrato" entre culturas diferentes, é também verdade que ele prevê um ato de apropriação e assimilação do Outro - ou seja, o Dom de si mesmo ao mundo é precedido por um sacrifício do mundo sobre o altar do sujeito, por um "dom do Outro",

14. FIMIANI, Mariapaola. L'arcaico e l'attuale. Lévy-Bruhl Mauss Foucault. Torino: Bollati Boringhieri, 2000. p. 119.

15 Idem, ibidem, p. 120.

16 Sobre "A noção de dépense" no âmbito da estética e da ideologia de Georges Bataille, veja-se o ensaio com este título incluído na tradução italiana do seu livro BATAILLE, Georges. La parte maledetta. Verona: Bertani, 1972. p. 41-57 (ed. or.: La part maudite. Paris: Minuit, 1967). Mais em geral, sobre a relação entre as posturas teóricas de Bataille e de Oswald, cf. LIMA, L. Costa. Antropofagia e controle do imaginário. In: Revista Brasileira de Literatura Comparada, 1, p. 62-75, 1991.

17 Sobre o caráter "não (a)presentável” do Dom, cf. sobretudo DERRIDA, Jacques Derrida. Donare il tempo. Milano: Cortina, 1996. p. 11 (ed. or.: Donner le temps. Paris: Galilée, 1991). Sobre a ambiguidade semântica do "presente" nas línguas românicas, ver também NANCY, Jean-Luc. L'esperienza della libertà. Torino: Einaudi, 200o. p. 153 (ed. or.: L'expérience de la liberté. Paris: Galilée, 1988) - análise levando à conclusão que o Dom é aquilo cuja "apresentação não se esvai numa presença acabada”. 
que é necessário para a constituição e identificação do Eu. Isto, falando não mais dentro de uma perspectiva econômica ou mercantilista, mas do interior de uma economia do desejo, que delineia uma estranha circularidade na qual a subjetividade se doa, tendo, porém, incorporado o objeto dentro de si mesma - e não, repare-se, o objeto real, mas, como já sublinhei, o seu fantasma, alimentando por isso a fantasia de uma plenitude que é apenas reiteração da carência do sujeito, do seu ausentar-se na reafirmação difícil e orgulhosa da presença.

Muitos (sobretudo a partir das análises de Derrida) sublinharam esse caráter intransitável do Dom, essa aporia pela qual só se doa aquilo que não se tem. Do mesmo modo, acho que se poderia afirmar que na verdade o "dom do Outro" (na sua dupla acepção gramatical) ${ }^{18}$, a sua devoração por parte do Eu, configura apenas a apropriação de um na$d a$-que-é, de um vazio que guarda, todavia, a capacidade de durar. E na Antropofagia estaria, justamente, em ação este mecanismo: doar uma cultura de que não se dispõe ou que já desapareceu (a indígena) e receber em troca um dom inexistente (a cultura europeia, considerada como um corpus homogêneo, como um todo a ser consumido). Nesta paradoxal simetria do "duplo ausente" tudo parece esvair-se, deixando apenas lugar para um trabalho inútil (melancólico) de elaboração do luto (do Outro) e da falta (do Eu). Se assim não é, é porque neste lidar com a duplicidade, neste movimento de ida e volta entre nada e nada, nesse vaivém entre fantasmas, alguma coisa fica - e aquilo que resta é, justamente, o entre-lugar ou o entre-tempo, aquele limiar terceiro e fictício sobre o qual se detém e se define a cultura brasileira, na sua natureza residual e anacrônica ${ }^{19}$. Para além do "desperdício" e do "contrato", em suma, a identidade brasileira se delineia, graças a uma economia do Dom, como resultado precário e sempre inatual de uma mescla penosa entre Eu e Outro, entre dentro e fora, que não nega a unidade, mas a penetra, a atravessa e transcorre por ela, até chegar a tecer uma forma diferente de união na diferença, uma trama peculiar de relações entre culturas que existem apenas como polos de uma dialética inconclusa e inconcludente - "gratuita" e "fastuosa" como o Dom, justamente ${ }^{20}$.

18 Cf. a esse respeito, ROVATTI, Pier Aldo. Il dono dell'altro. In: FERRETI, Giovanni (Org). Il codice del dono: verità e gratuità nelle ontologie del novecento. Atti del IX colloquio su filosofia e religione, Macerata 2002. Pisa-Roma: IEPI, 2003. p. 123-32.

19 Cf. ainda GOMES, R. Cordeiro. op. cit., p. zo. Veja-se também, sobre esse third space em que se situam as culturas pós-coloniais, BHABHA, Homi. op. cit., p. 36-39 e 217-19.

20 Cf. FIMIANI, Mariapaola. L'arcaico e l'attuale. Lévy-Bruhl Mauss Foucault. op. cit., p.128. Acho, por isso, não congruente com essa dialética imperfeita, a ligação "necessária”, postulada por Paul Ricoeur, entre doar e perdoar (RICOEUR, Paul. La mémoire, l'histoire, l'oubli. Paris: Seuil, 200o. p. 595-642): a própria etimologia - 
Quero, com isso, dizer (como já disse em outro texto) ${ }^{21}$ que o duplo que se cava na falta todavia delimita uma dimensão de sentido, um tempo que sobra e que resta, assim como sobra e resta o produto dessa antropofagia fantasmática teorizada por Oswald de Andrade: nada que possa ser proposto como Dom real ou recebido como dádiva do Outro, mas apenas esse restante impalpável que a metabolização da cultura europeia por parte da brasileira deixa atrás de si. Retomando a metáfora do fluxo, eu diria que justamente dentro desse dinamismo das relações entre sujeitos culturais, na fluência infinita das trocas ou dos dons de objetos imateriais, a identidade cultural consegue se definir só enquanto enseada ou charco, apenas como aquilo que precariamente se detém e fica no interior do fluxo: pequeno grumo de resistência, que não tem tempo ou espaço próprios dentro da fluidez global dos contornos, mas que, todavia, configura uma fresta, uma abertura, que não pode ser pactuada ou definida, por ser ela mesma limite, margem de liberdade sobre a qual devemos sem fim habitar. Porque (tanto na época do Modernismo, eu diria, quanto na nossa era globalizada) é apenas esse entre, esse lugar terceiro, ao mesmo tempo melancólico e "festivo", aquilo que resta e que nos salva. Posto que - parafraseando o título de uma famosa estória de Guimarães Rosa em que assistimos, justamente, a um doar "de mãos cheias" ${ }^{22}$ e sem contrapartida - porque, finalmente, esse quase-nada é (só ele, na verdade, pode ser) a nossa incerta condição.

que volta idêntica em muitas línguas, como o próprio filósofo sublinha - indica, a meu ver, que o segundo termo, rematando o primeiro, faz por isso do Giving um For-giving, um "dar a" para apagar uma culpa e reconstruir, assim, uma situação de equilíbrio, enquanto a economia do dom (já em Mauss) aparece como suspensa num espaço ambivalente e aberto, não permitindo nenhum perdão ou esquecimento, nenhuma estabilidade ou redenção. Quero, aliás, que esta afirmação seja entendida como uma modesta homenagem - dialógica, porém, cheia de admiração e gratidão - a um Mestre que nos encheu de "dons" e que acaba de nos deixar.

21 Veja-se o meu FINAZZI-AGRÒ, Ettore. O duplo e a falta: construção do outro e identidade nacional na literatura brasileira. Revista Brasileira de Literatura Compara$d a, 1$ (1991), p. 52-61, 1991.

22 Esta expressão alude ao título da tradução italiana (STAROBINSKI, Jean. A piene mani: dono fastoso e dono perverso. Torino: Einaudi, 1999) do importante volume de Jean Starobinski sobre a representação do Dom no âmbito artístico, originariamente intitulado Largesse ( Largesse. Paris: Editions de la Réunion des Musées nationaux, 1994). 